\title{
Potential suitable habitat of Eleusine coracana (L) gaertn (Finger millet) under the climate change scenarios in Nepal
}

\author{
Dol Raj Luitel ${ }^{1,2^{*}}$, Mohan Siwakoti ${ }^{1}$, Mohan D. Joshi ${ }^{3}$, Muniappan Rangaswami ${ }^{4}$ and Pramod K. Jha ${ }^{*}$
}

\begin{abstract}
Background: Finger millet is the fourth major crop in Nepal and is cultivated in a traditional integrated subsistence system. Timely rain and appropriate temperature predominately affects crop distribution and yield. Climate change is evident in Nepal and it is imperative to understand how it affects habitat suitability of finger millet. Main objective of this study was to map the current suitable habitat and predicting the potential changes in the future under different climate scenarios in Nepal. Habitat mapping is important for maximizing production and minimizing the loss of local landraces.

Results: Maxent model was used in this study to quantify the current suitable habitat and changes in the future habitat suitability of finger millet, based on representative concentration pathways (RCP) (RCP 2.6, 4.5, 6.0 and 8.5) in two different time periods (2050 and 2070AD) using climatic predictive variables and species localities. The model shows that $39.7 \%\left(58512.71 \mathrm{~km}^{2}\right.$ ) area of Nepal is highly suitable for finger millet, with cultivation mostly between 96 and $2300 \mathrm{~m}$ above sea level. Eastern and central parts of Nepal have more suitable areas than western parts. Our research clearly shows that the future climatic suitable area of finger millet would shrink by 4.3 to $8.9 \%$ in 2050 and 8.9-10.5\% under different RCPs by 2070.
\end{abstract}

Conclusion: Finger millet is mostly cultivated in mid-hill terraces. The substantial increase in temperature due to climate change may be one reason for decrease in habitat suitability of finger millet. This situation would further threat loss of local landraces of finger millet in the future. The findings can help in planning and policy framing for climate resilient smart agriculture practice.

Keywords: Climate change, Finger millet, Habitat suitability, Maxent model

\section{Background}

Nepal, having an area of $147,181 \mathrm{~km}^{2}$, lies on the southern slope of the Central Himalayas. It has a wide range of variation in physiographic, topographic, climatic and edaphic conditions, and has tropical to tundra climate within a narrow range of $185 \mathrm{~km}$ North-South. Rice, wheat, maize, finger millet and buckwheat are the major

\footnotetext{
*Correspondence: luiteldr2@gmail.com; pkjhaprof@gmail.com ${ }^{1}$ Central Department of Botany, Tribhuvan University, Kirtipur, Kathmandu, Nepal
}

Full list of author information is available at the end of the article cereal crops. Agriculture is the major source of economy, contributing $32 \%$ of total GDP and employing $63 \%$ of the population. The rural population of Nepal depends primarily on traditional subsistence, rain-fed agricultural practice, which is climate dependent [1]. Finger millet [Eleusine coracana (L.) Geartn, family: Poaceae], the fourth major crop in Nepal, occupies an important role in Nepalese agriculture, especially in mountainous remote areas [2]. It is considered an under-exploited, poor person's, neglected crop, cultivated mostly in mid-hills and mountainous regions $[3,4]$. 
Finger millet is the fourth cereal in term of area and production after rice, wheat and maize with total cultivation area was 265,496 ha in 2007 and 263,596 ha in 2017. The national production of finger millet was 291,098t in 2007and increased to 306,704t in 2017 [2]. The increase in production of this crop cannot fulfill the national demand so it is being imported from neighboring countries. The import of finger millet was 1217t in 2017 [2]. It is evident that both the national demands as well as yield are continuously increasing. Finger millet's grain is rich in protein, dietary fiber and minerals especially calcium, iron, zinc and phosphorus as compared to other cereals $[5,6]$ and play an important role in food and nutrition security in areas where they are grown [7].

Future projections based on four representative concentration pathways (RCPs) (2.6, 4.5, 6.0 and 8.5) show that the earth's temperature will increase by $2.6-3.8^{\circ} \mathrm{C}$ by $2100 A D$. In Nepal, the mean annual temperature is projected to increase by $1.4^{\circ} \mathrm{C}$ by $2030,2.8^{\circ} \mathrm{C}$ by 2060 , and $4.7^{\circ} \mathrm{C}$ by 2090 . Based on the Regional Circulation Model $(\mathrm{ReCM})$, the total precipitation and its intensity may increase by $15-20 \%$ during the summer currently [8]. The total precipitation is projected to increase by $6 \%$ and $12 \%$ by 2050 and 2090, respectively [9]. However, precipitation projection from observed historical trends shows a decrease in post-monsoon rainfall [10] with more erratic, heavy, and unpredictable rain within shorter periods, potentially leading to extreme drought [11]. Similarly, the annual precipitation of Nepal has increased by $13 \mathrm{~mm}$ and days of rainfall have decreased by 0.8 days per year since 1990 [12]. These changing patterns of climatic variables are expected to severely affect crop production, livelihoods, and food security in Nepal [13].

Species distribution modelling (SDM) is one of the simple and quick tools for identifying the climatic changes and projections of climatic impacts on species and can be used to match adaptation policies and practices [14, 15]. Understanding exact suitable area and predicting future suitable area of a crop is essential for understanding further expansion or shrinkage of cultivation areas that may open new avenues for rescuing neglected local landraces. In Nepal, studies on the effects of climatic variables on modeling for habitat suitability of minor crop species are virtually absent. This work not only fills that knowledge gap, but also opens new avenues for analyzing the habitat of crop species in response to different environmental variables and predicts the habitat suitability by using the machine learning software Maxent [16].

\section{Results}

Contribution of predictor variables and model accuracy

From the Jackknife analysis, among the nine bioclimatic variables used for modeling altitude (nalt), annual rainfall (nbio12), slope of the region (nslope), and soil (nsotar) together contributed about $93 \%$ in predicting the suitable habitat of finger millet (Fig. 1). Altitude (nalt) had the highest contribution of $33.8 \%$, followed by annual rainfall (nbio12) with $32.4 \%$ contribution to the model. The mean temperature of the driest quarter (nbio9), aspect (naspect), mean diurnal range (nbio2), and temperature seasonality (nbio4)variables showed the least contributions, but the isothermality (nbio3) showed no contribution (Fig. 1).

Overall accuracy was high $(>0.80$, which refers to $80 \%$ accuracy) for predictions under present and future time periods by AUC. The model performances evaluated by different statistic score/matrices are given in Table 1 . Validity of the model for current habitat suitability of finger millet was strong with $\mathrm{AUC}=0.832$, indicating that the variables used in modeling described well to determine the habitat suitability of finger millet in Nepal. The AUC, prediction accuracy of the model used for analyzing the distribution under present and future time period of finger millet, ranged from 0.806 to 0.845 , TSS between 0.576 and 667, and the Kappa between 0.601 and 0.631.

\section{Distribution of suitable habitat}

Under present climatic scenario, the overall distribution of most suitable habitat of finger millet lies between 500 and $1500 \mathrm{~m}$ elevation above the sea level (asl) although it occurs between the elevation range between 96 and $2300 \mathrm{~m}$ asl (Fig. 2a and Table 3). In the current scenario, total suitable habitat for finger millet cultivation was $39.7 \%\left(58512.71 \mathrm{~km}^{2}\right.$ ) (Table 2). Physiographically, the predicted potential habitat suitability suggested that the most suitable areas for finger millet are the Siwalik, midhill, and lower part of mountain region of Nepal (Fig. 2a). Similarly, the central and eastern part of the country is more suitable than the western parts.

\section{Future distribution suitability scenarios (stable, loss and gain area)}

The distribution of suitable area of finger millet under current and future conditions is presented in Fig. 3. In the future distribution of finger millet, the stable, gain, and loss area are presented in solar yellow, green, and red color, respectively, for no change, increase, and loss in each figure (Fig. 2b-i).

By undertaking visual inspection of the model prediction based on current climatic conditions and occurrence records, it is clear that the western part of the country is comparatively less suitable than eastern and central parts. The future distribution reveals the shift of habitat towards the northeast but reduces the total suitable area in the year 2050 and 2070 as compared to the current situation (Fig. 2). 


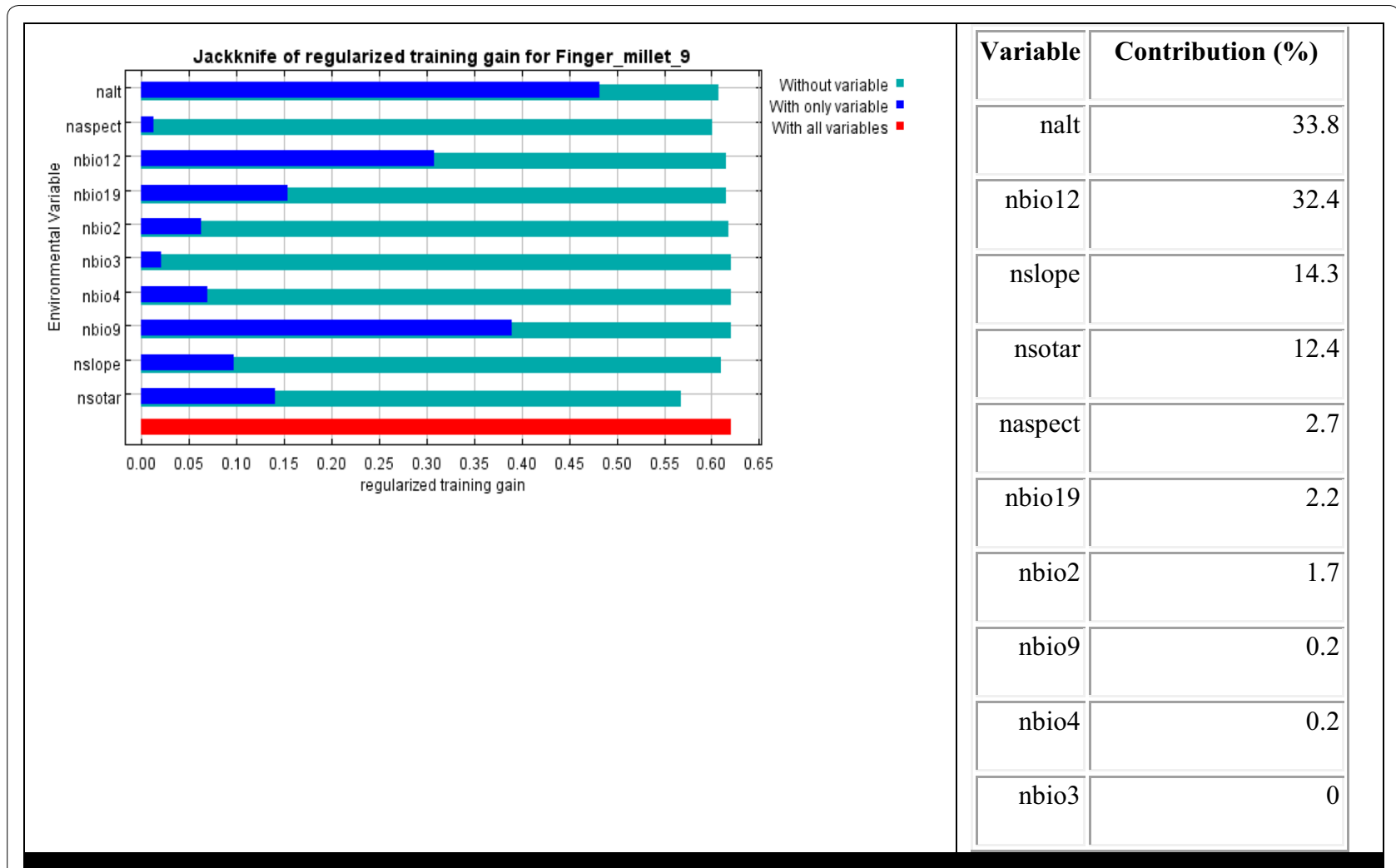

Fig. 1 The results of the Jackknife test on variables' contribution to modelling finger millet habitat suitability. The regularized training gain describes how much better the Maxent distribution fits the presence data compared to a uniform distribution. The dark blue bars indicate the gain from using each variable in isolation, the light blue bars indicate the gain lost by removing the single variable from the full model, and the red bar indicates the gain using all of the variables. The contribution of individual variables is presented in right side within the figure

Table 1 Prediction accuracy of habitat suitability in distribution modeling of finger millet

\begin{tabular}{|c|c|c|c|c|c|c|c|c|c|}
\hline $\begin{array}{l}\text { Model } \\
\text { Evaluator }\end{array}$ & Current & $\begin{array}{l}\text { RCP2.6_ } \\
2050\end{array}$ & $\begin{array}{l}\text { RCP } 2.6 \text { - } \\
2070\end{array}$ & $\begin{array}{l}\text { RCP4.5 } \\
2050\end{array}$ & $\begin{array}{l}\text { RCP4.5_ } \\
2070\end{array}$ & $\begin{array}{l}\text { RCP6.0_ } \\
2050\end{array}$ & $\begin{array}{l}\text { RCP6.0_ } \\
2070\end{array}$ & $\begin{array}{l}\text { RCP8.5_ } \\
2050\end{array}$ & RCP8.5_2070 \\
\hline AUC & 0.832 & 0.833 & 0.841 & 0.845 & 0.841 & 0.838 & 0.838 & 0.806 & 0.838 \\
\hline Sensitivity & 0.866 & 0.868 & 0.865 & 0.852 & 0.904 & 0.852 & 0.847 & 0.863 & 0.863 \\
\hline Specificity & 0.712 & 0.799 & 0.704 & 0.773 & 0.741 & 0.758 & 0.7150 & 0721 & 0.742 \\
\hline TSS & 0.576 & 0.667 & 0.617 & 0.626 & 0.645 & 0.610 & 0.608 & 0.584 & 0.605 \\
\hline $\begin{array}{l}\text { Kohan's } \\
\text { Kappa }\end{array}$ & 0.621 & 0.607 & 0.606 & 0.631 & 0.601 & 0.616 & 0.622 & 0.616 & 0.626 \\
\hline
\end{tabular}

Our analysis shows that by 2050 there will be decrease in suitable habitat by $4.2 \%, 4.3 \%, 4.8 \%$ and $3.8 \%$ in RCP's 2.6, 4.5, 6.0 and 8.5, respectively (Table 2). The total loss area in different RCP's analysis shown by 2050 ranges from 3.9 to $8.9 \%$ over the current suitable habitat area and $8.9-10.5 \%$ area will be lost by 2070 . Similarly, the suitable habitat will gain by $6.1,4.1,3.8$ and $4.6 \%$ in RCP's $2.6,4.5,6.0$ and 8.5 , respectively, by 2050 and by $5.6,3.8$, 2.9 and $4.1 \%$, respectively, by 2070 (Table 2, Fig. 2 b-i).
Changes in potential suitable area under climate change scenarios

The predicted suitable area for finger millet under the RCP2.6 climate change scenario would decrease by $3.5 \%$ under 2.6 RCP by 2050. Similarly, the net suitable area for finger millet would be lostby $0.4 \%$ and $5.1 \%$ in RCP 4.5 and 6.0 by 2050 , respectively. However, $0.7 \%$ area would be gained under extreme conditions of climate i.e. 8.5 RCP by 2050 (Table 2, Fig. 2).The net suitable area would 


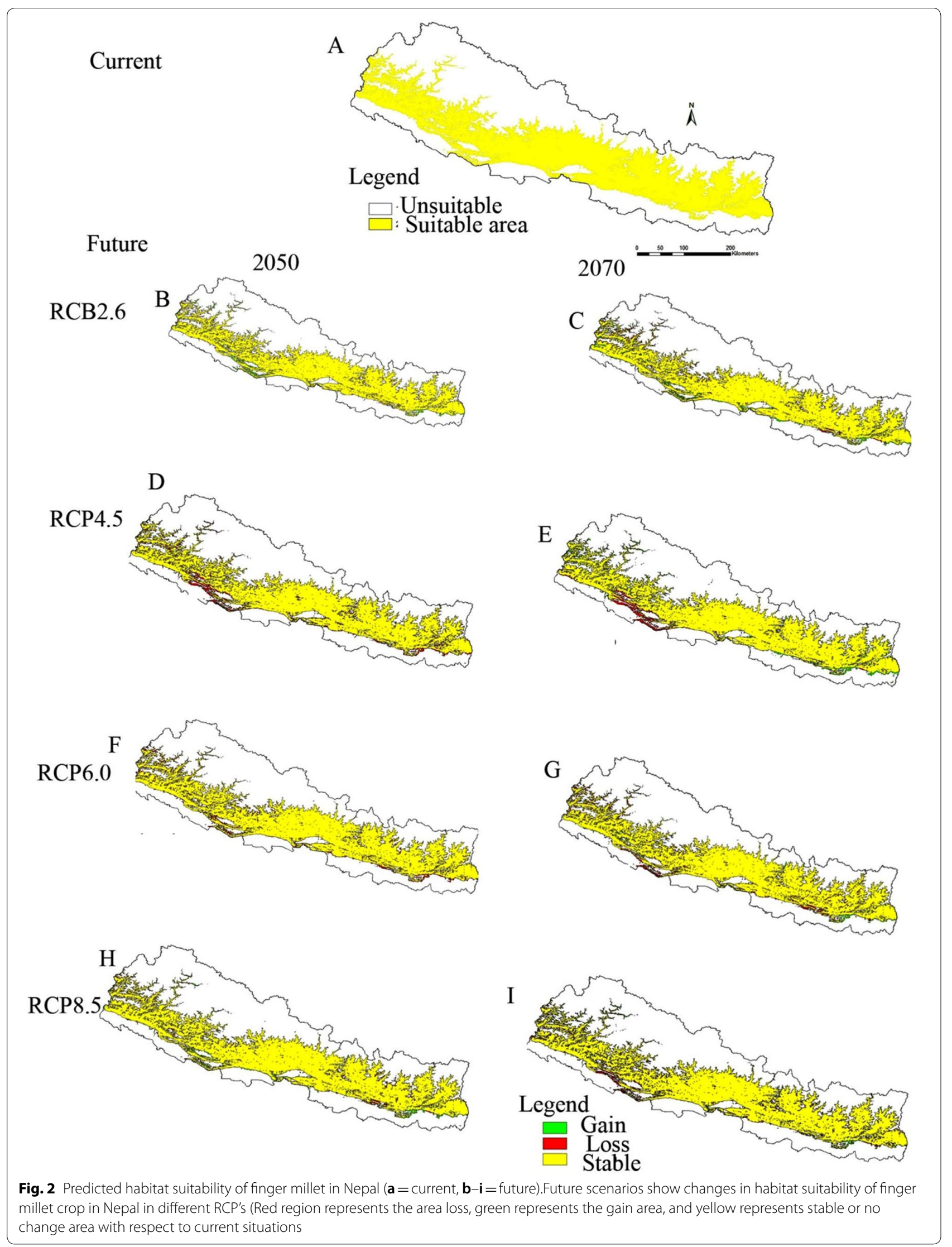


Table 2 Habitat stability, gain and loss area $\mathrm{Km}^{2}$ of finger millet under different RCPs in 2050 and 2070

\begin{tabular}{llllll}
\hline Climatic scenarios & Stable area & Gain area & Loss area & Net gain or loss area & Significance \\
\hline Current & $58512.71(100)$ & & & & \\
Future & & & & & \\
RCP 2.6_year 2050 & $56082.51(95.8)$ & $3401.74(6.1)$ & $2436.77(4.3)$ & $+964.97(1.8)$ & Yes \\
RCP 2.6_year 2070 & $56599.69(96.7)$ & $3197.33(5.6)$ & $5133.6(9.1)$ & $-1936.27(3.5)$ & Yes \\
RCP 4.5_year 2050 & $56018.34(95.7)$ & $2248.46(4.1)$ & $2511.68(4.5)$ & $-263.22(0.4)$ & Yes \\
RCP 4.5_year 2070 & $55716.17(95.2)$ & $2120.07(3.8)$ & $4932.29(8.9)$ & $-2812.22(5.1)$ & Yes \\
RCP 6.0_year 2050 & $55716.17(95.2)$ & $2120.07(3.8)$ & $4932.29(8.9)$ & $-2812.22(5.1)$ & Yes \\
RCP 6.0_year 2070 & $54436.83(93.1)$ & $1595.15(2.9)$ & $5689.2(10.5)$ & $-4094.05(7.6)$ & Yes \\
RCP 8.5_year 2050 & $56357.93(96.3)$ & $2594.41(4.6)$ & $2166.39(3.9)$ & $+428.02(0.7)$ & Yes \\
RCP 8.5_year 2070 & $55184.56(94.3)$ & $2248.46(4.1)$ & $5590.8(10.2)$ & $-3342.34(6.1)$ & Yes \\
\hline
\end{tabular}

Figure in parentheses is percentage of area

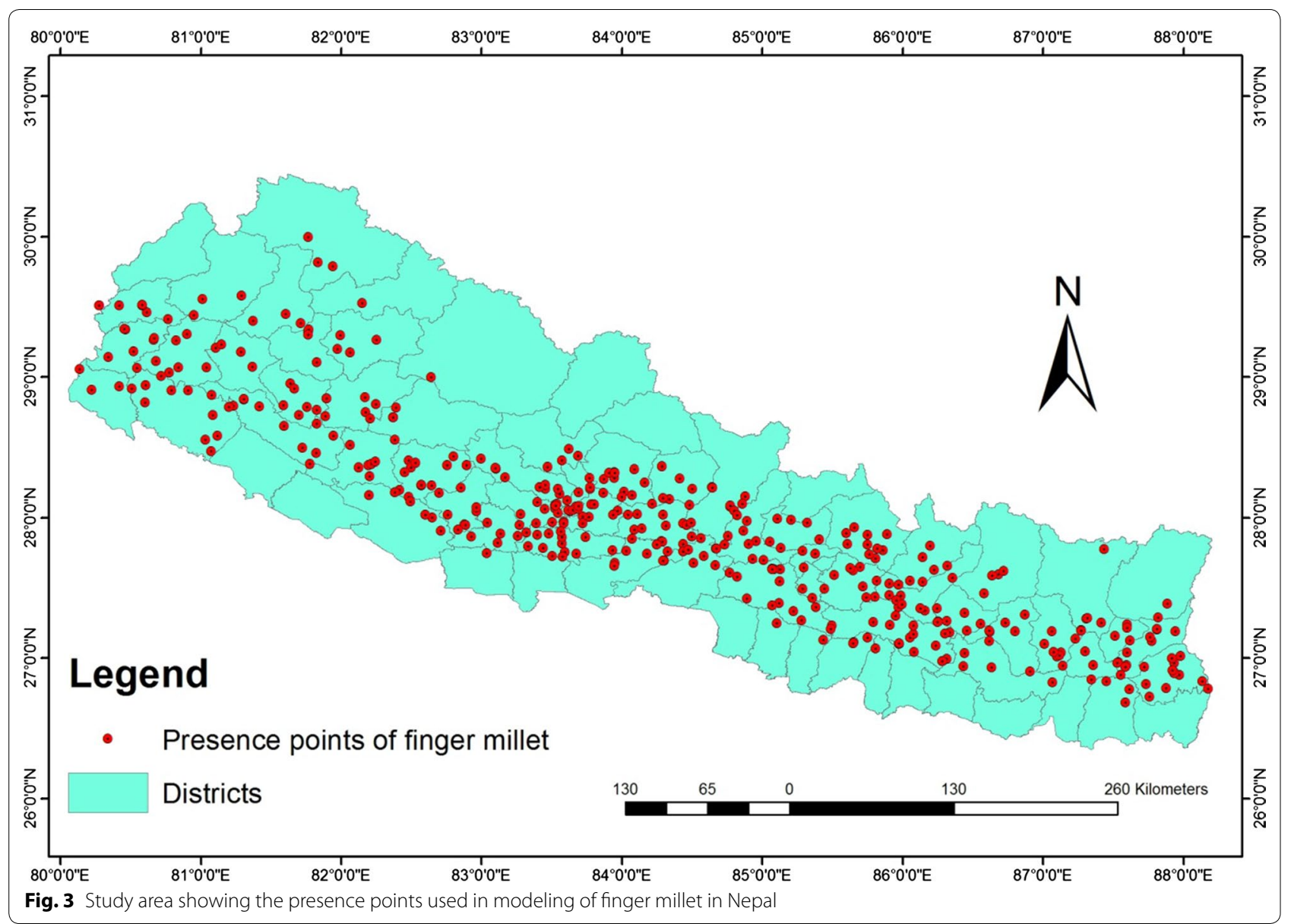

continue to be lost by 3.5 to $7.6 \%$ under different RCPs by 2070.

By 2050, in RCP's 2.6, the major area will shrink in far western Nepal, specifically in Mahakali and Karnali regions in west, and some areas like Sagarmatha and Koshi regions in the east. There may be addition of some areas in the mid-western region of Nepal (Fig. 2b) and there is almost a similar trend for 2070 in 2.6 RCPs (Fig. 3c). In RCP's 4.5, for both year 2050 and 2070, the major part of suitable area for finger millet will be lost in mid and far regions (Fig. 2d, e). In RCP's 6.0, the suitable area will shrink throughout the country especially 
Table 3 The predicted uppermost and lowermost elevation range of finger millet suitable habitat in Nepal

\begin{tabular}{|c|c|c|}
\hline \multirow[t]{2}{*}{ Scenarios } & \multicolumn{2}{|l|}{ Suitable elevation range } \\
\hline & Minimum altitude (m) & $\begin{array}{l}\text { Maximum } \\
\text { altitude }(\mathrm{m})\end{array}$ \\
\hline Current & 96 & 2300 \\
\hline \multicolumn{3}{|l|}{ Future } \\
\hline \multicolumn{3}{|l|}{ RCP 2.6} \\
\hline Year 2050 & 89 & 2191 \\
\hline Year 2070 & 87 & 2175 \\
\hline \multicolumn{3}{|l|}{ RCP 4.5} \\
\hline Year 2050 & 97 & 2151 \\
\hline Year 2070 & 96 & 2187 \\
\hline \multicolumn{3}{|l|}{ RCP6.0 } \\
\hline Year 2050 & 87 & 2186 \\
\hline Year 2070 & 94 & 2198 \\
\hline \multicolumn{3}{|l|}{ RCP 8.5} \\
\hline Year 2050 & 96 & 2097 \\
\hline Year 2070 & 98 & 2083 \\
\hline
\end{tabular}

in upper mountain and lower parts of mid-hills, with the exception of some of the areas (Fig. 2f, g) for both 2050 and 2070. There will almost be a similar pattern followed for RCPs 8.5 for 2050 and 2070 (Fig. 2h, i).

At present, the most suitable habitat for finger millet is between 96 and $2300 \mathrm{~m}$ asl in Nepal, but is more concentrated in eastern and central Nepal. However, moderate suitable (probability of suitability in between 25 and 50\%) area ranged from 75 to $3034 \mathrm{~m}$. In the future, most suitable habitat will shrink from $2300 \mathrm{~m}$ to $2151 \mathrm{~m}$ in RCP 4.5 in year 2050 and further shrinkage to $2097 \mathrm{~m}$ asl in RCP 8.5 in year 2050 in Nepal. Similarly, there will be a decrease in suitable habitat for $2187 \mathrm{~m}$ to $2083 \mathrm{~m}$ under 4.5 and $8.5 \mathrm{RCP}$ in year 2070 (Table 3).

\section{Discussion}

The coverage of climatically suitable habitats was modeled for the first time in Nepal to delineate the potential suitable habitat of finger millet under current and future climate change scenarios.

Finger millet is relatively resistant to different stress conditions like high temperature, drought, and salinity of soil [30] and this crop follows photosynthetically efficient $\mathrm{C} 4$ pathway. Climate change projections reveal increased temperature by $4.7^{\circ} \mathrm{C}$ in higher altitude areas of Nepal Himalayas within 2090 AD as well as monsoon rainfall likely to increase in erratic pattern by 2090 [8]. Our results clearly indicate that significant shrinkage of existing suitable area will occur with rising temperatures within 2050 by $3.9-10.3 \%$ and by $4.3-10.5 \%$ in 2070; however, there may be addition of suitable area by
$4.6-5.6 \%$ within 2050 and $2.9-6.1 \%$ by 2070 under different RCPs in Nepal. No particular trend of loss and gain in the future were shown by the model, but net suitable area will be lost in 2050 and 2070 as compared to the current situation. Several climate related factors may play a role in the decline of suitable area of finger millet including drought, rise in maximum temperature, increasing erratic pattern of rainfall, and the shift of bioclimatic zones in different elevations in Nepal [31]. There was loss of agricultural land from Nepal during the period of 1971-2007 due to climate related catastrophes like droughts, flood, hailstorm, rain, strong winds, and cold wave. Around $38 \%$ of overall agricultural land loss was seen due to drought alone [32]. The projected suitable habitat losses mostly from mountains in western Nepal may be due to increase in drought in these regions because annual rainfall is the predictor variable with highest contribution in model performance in this study (Fig. 1).

The impact of climate change on suitable habitat would be mixed loss in suitable habitat in western region and some additional of suitable area in eastern and central parts are expected. A mixed impact of climate change on crops has been shown in banana and coffee in Nepal. With the change in climate, the suitable habitat of banana would increase, but that of coffee would worsen [33].

The addition of suitable area for finger millet in Nepal and downward shrinkage of highest elevation for cultivation from 2300 to $2080 \mathrm{~m}$ may be due to change in the average growing degree days (GDD) for finger millet from North to South [34] as temperature is one of the main limiting factors for crops, especially in temperate zones [35]. GDD is a measure of the heat a plant requires to mature and yield a successful crop. The predicted average rise in temperature of about $4.7{ }^{\circ} \mathrm{C}$ by 2090 [8] may not fulfill the daily air temperature at higher altitude during the growing season. Similarly, projected increases in erratic summer rainfall along with sharp slopes in the mountains are other limiting factors of the suitability of finger millet crop area from western parts of the country.

Changes in climatic conditions in the future will not only affect the crop distribution, but also its quality. Research conducted in the USA shows that the seasonlong high temperature stress reduces the chlorophyll index, seed number, grain yield and harvest index; however, only a few genotypes of finger millet show tolerance with high temperature [36]. Therefore, climate change will have at least double impact on finger millet production-first, shrinkage of suitable area, and second, the reduction in grain yield.

Siwalik and mid-hills between the elevation 500$1500 \mathrm{~m}$ have maximum suitable habitat for finger millet (Fig. 2a). Mid-hills in Gandaki, Lumbini, Sagarmatha regions of Nepal are the highest producers of finger millet 
[37], which is correctly reflected in the model results. However, from the visual estimation of model output in Fig. 2, the model means normally over estimatedthe suitable habitat in Mechi, Koshi, and Narayani regions and underestimated for Karnali regions (Fig. 2b-i). Nevertheless, high AUC, TSS and Kappa values suggest that the model has excellent level of accuracy (Table 1). The model accuracy has been verified with the comparison of elevation under current scenario and recorded elevation by other researchers. Based upon the literature, Kachorwa village (85 masl) of Bara district [38] is the lowest elevation and Borounse village (3130 masl) of Humla district [4] is the highest point of current cultivation in Nepal. From this model, the current moderate suitable (having probability in between 25 and 50\%) climate for finger millet ranges between 75 and $3034 \mathrm{~m}$ asl, though most suitable area (having probability $>50 \%$ ) lies in between 96 and $2300 \mathrm{~m}$. This model prediction almost matched with the reality of current distribution of finger millet cultivation in Nepal.

\section{Conclusions}

Maxent modeling for finger millet crop clearly defined the current suitable area for the cultivation and potential suitable areas in 2050 and 2070AD. The model revealed that $39.7 \%\left(58512.71 \mathrm{~km}^{2}\right)$ area of Nepal is the most suitable habitat for finger millet, between 96 and $2300 \mathrm{~m}$ elevations, though only $4.5 \%$ of most suitable land is under cultivation at present cultivated land use of Nepal. Similarly, eastern and central parts of Nepal have more suitable areas than western parts. Our research clearly showed that the future climatic suitability of finger millet would shrink up to $10 \%$ under different RCPs from Nepal in 2070 and about 6\% additional suitable area will emerge due to changing scenarios of climatic variables, by 2050 and 2070.The suitable habitat will decrease in the western mountain region (Karnali and Mahakali regions) as compared to other parts of the country. Although $10 \%$ suitable land would be lost due to climate change by 2070 , another nearly $3-6 \%$ climatically suitable area would be available for finger millet cultivation, especially from mid land areas of the country. These findings help to develop the strategies to cultivate finger millet at climatically suitable area to fulfill the national demand.

\section{Materials and methods}

\section{Crop species and location points}

Finger millet (Eleausine coracana) was selected for modeling and its habitat suitability under climatic change scenarios. The diversity of finger millet (Eleusine sp.) is quite high, indicating that Nepal is one of the centers of origin [17], but a number of local landraces are either getting lost or on the verge of extinction. A total of 352 occurrence points of finger millet were collected from the field survey from 19 districts of central Nepal. In order to reduce the sampling biases in the location data of central Nepal, spatial filtering of occurrence points was used, employing fishnet option in Arc GIS10.3, which reduced the presence points to 101 for better performance of the model [18]. An additional 53 points were collected from the database of National Agriculture Genetic Resource Centre (NAGRC) and 250 points were collected from geo-referencing, principally based on the records of NAGRC that included spatial location names without geological coordinates. Thus, a total of 404 presence points of finger millet for the whole of Nepal were employed in Maxent model (Fig. 3).

\section{Bioclimatic variables}

For current and future time periods (2050 and 2070 AD), all 19bioclimatic variables (bio30s) on 30-arc-sec resolution at ESRI grids format were downloaded from Worldclim dataset [19].The Community Climate System Model $\left(\mathrm{CCSM}_{4}\right)$ [20] was followed under Representative Carbon Pathway of RCP 2.6, RCP4.5, RCP 6.0and RCP 8.5 for future (year 2050 and 2070) because $\mathrm{CCSM}_{4}$ is mostly used in South-Asian region for modeling. These data were statistically downscaled from Global Circulation Model (GCM) using Worldclim 1.4 at present baseline climate. The altitude, slope, and aspect were derived from the digital elevation data based on Shuttle Radar Topographic Mission (SRTM) at $90 \mathrm{~m}$ spatial resolution and were re-sampled to 30 arc second spatial resolutions to match with the resolution of climatic variables (Table 4). The raster data from the global scale was masked for Nepal. All RCPs (RCP's 2.6, 4.5, 6.0 and 8.5) greenhouse concentration trajectories for two different time periods (2050 and 2070) were selected to determine the future habitat suitability of species. The lowest greenhouse concentration (GHG) pathway is RCPs 2.6 (aggressive mitigation/lowest emissions), while RCPs 4.5 and RCPs 6.0 are intermediate, and RCPs 8.5 (highest emission scenario) is maximum. GHG concentration pathways in which radioactive forcing (global energy imbalance) stabilizes $2.6 \mathrm{~W} / \mathrm{m}^{2}, 4.5 \mathrm{~W} / \mathrm{m}^{2}, 6.0 \mathrm{~W} / \mathrm{m}^{2}$ and $8.5 \mathrm{~W} / \mathrm{m}^{2}$, respectively, by $2100[21,22]$.

Among the 22 variables (19 bioclimatic variables, slope, aspect and altitudes), pair wise correlation and Variation Inflation Factors (VIFs) were performed by using statistical software $\mathrm{R}$ [23] to test the multi co-linearity among the environmental variables. The highly correlated bio-variables with a Pearson correlation ( $\mathrm{r} . \leq \pm 0.80$ ) and VIF $>5$ were omitted in order to reduce the effect of multi-co-linearity among the variables, which enables over fitting of the model [24, 25]. 
Table 4 Bioclimatic variables used for modelling habitat suitability of finger millet in Nepal

\begin{tabular}{|c|c|}
\hline Code & Variables \\
\hline nbio_1 & Annual mean temperature \\
\hline nbio_2 & $\begin{array}{l}\text { Mean diurnal range (mean of monthly (max } \\
\text { temp—-min temp)) }\end{array}$ \\
\hline nbio_3 & Isothermality (Bio_2/Bio_7) (*100) \\
\hline nbio_4 & Temperature seasonality (standard deviation *100) \\
\hline nbio_5 & Max temperature of warmest month \\
\hline nbio_6 & Min temperature of coldest month \\
\hline nbio_7 & Temperature annual range (Bio_5-Bio_6) \\
\hline nbio_8 & Mean temperature of tettest quarter \\
\hline nbio_9 & Mean temperature of driest quarter \\
\hline nbio_10 & Mean temperature of warmest quarter \\
\hline nbio_11 & Mean temperature of coldest quarter \\
\hline nbio_12 & Annual precipitation \\
\hline nbio_13 & Precipitation of wettest month \\
\hline nbio_14 & Precipitation of driest month \\
\hline nbio_15 & Precipitation seasonality (coefficient of variation) \\
\hline nbio_16 & Precipitation of wettest quarter \\
\hline nbio_17 & Precipitation of driest quarter \\
\hline nbio_18 & Precipitation of warmest quarter \\
\hline nbio_19 & Precipitation of coldest quarter \\
\hline nslope & Slope \\
\hline naspect & Aspect \\
\hline nsotar & soil \\
\hline
\end{tabular}

Source: worldclim.org

The remaining nine variables viz. aspect, slope, mean diurnal range (mean of monthly\{max temp-min temp\}), isothermality (Bio_2/Bio_7) ("100),temperature seasonality (standard deviation "100), mean temperature of driest quarter, annual precipitation, precipitation of coldest quarter and soil were used to model the habitat suitability of finger millet in current and future climatic conditions. All the bioclimatic data sets were converted into ASCII files in Arc GIS 10.3 to make the acceptable format for Maxent software. The same process was repeated to produce the projected maps in all future scenarios for the year 2050 and 2070 considering the soil condition to remain constant in the future under RCP2.6, RCP4.5, RCP6.0 and RCP8.5.

\section{Modeling by maxent}

The open source Maxent software (Maxent 3.4.1) was used to quantify (model) the current and future habitat suitability of finger millet cultivation area in Nepal. Maxent is a machine learning method that estimates the probability distribution of a species occurrence based on environmental conditions of a location in which the species is found by calculating the distribution of maximum entropy i.e. the most spread out distribution in space for a given set of constraints [16]. In this study, the Maxent software was modeled by applying the following parameters $-25 \%$ random test percentage, i.e. $75 \%$ of presence points data were used for training and the remaining $25 \%$ to test the predictive ability of Maxent model, 1 regularization multiplier, 10,000 maximum numbers of background points, 10 replicates, subsample replicate type, 5000 maximum iterations, 0.00001 convergence thresholds. The file format was set for logistic output, which provides predicted probabilities in between 0 and 1 and background prediction.

\section{Model validation}

The Area Under Receiver-operating Characteristic Curve (AUC), Kohan's Kappa and true skill statistic (TSS) were used for model evaluation [26].

The presence dataset was divided 75 percent into training data, which were used to build a model, and the remaining $25 \%$ for test data was used to test the model performance [27]. The values of AUC range from 0.5 to 1.0, with 0.5 indicating no (random) fit to the data, 1.0 indicating perfect model performance, $0.7-0.79$ reasonable, $0.8-0.89$, excellent, and values $>0.9$ indicating high performance [28]. The TSS account for both sensitivity and specificity and its values lie within +1 to -1 , where +1 indicates the perfect model performance [26]. To assess the importance of used variables to the model, Jackknife procedure was used.

The final potential distribution map with values 0 to 1 were grouped into two classes viz. 0.00 to 0.5 and 0.5 to 1.0. We considered pixels with or more than 0.50 value to consider areas that depict at least $50 \%$ probability of species cultivation suitability [29]. The stability gain and loss of predicted suitable area was calculated for future in each RCP scenario through Arc GIS 10.3. To calculate stability, gain and loss on predicted area, the final output map of Maxent was binarized (i.e. presence/absence) by using lowest value of 10 percentile training presence Logistic threshold of Maxent results. The stable, gain and loss of suitable area map was determined by using intersect and symmetrical analysis tools in Arc GIS 10.3.

\footnotetext{
Abbreviations

RCP: Representative concentration pathways; GDP: Gross domestic products; ReCM: Regional circulation model; SDM: Species distribution modelling; AUC : Area under receiver-operating characteristic curve; TSS: True skill statistic; NAGRC: National agriculture genetic resource centre; $\mathrm{CCSM}_{4}$ : Community climate system model; GHG: Green house gas; VIF: Variation inflation factors; Maxent: Maximum entropy.
}

\section{Acknowledgements}

This work was funded in whole by the United States Agency for International Development (USAID). Bureau of Food Security under the Cooperative Agreement No. AID-OAA-L-15-00001 as a part of Feed the Future Innovation Lab for 
Integrated Pest Management. Any opinions, findings, conclusions or recommendations expressed here are those of the authors alone. We are also thankful to Sara HENDERY for editing language, Dr. Deep Narayan Shah for his support and technical advice during the preparation of Worldclim data. Thanks to Scientist Deepa Singh, National Agriculture Genetic Resource Centre (NAGRC), Gene Bank, Khumaltar for providing occurrence points of finger millet.

\section{Authors' contributions}

DRL, primary researcher, designed concept collected field data, gathering and processing of all data source, and prepared manuscript. MS, MDJ and PKJ participate in its design, supervised the works and edited the manuscript. MR was involved in interpretation of results. All authors read and approved the final manuscript.

\section{Funding}

This research was supported by Feed the Future Innovation Lab for Integrated httPest Management funded by the United States Agency for International Development (USAID) under the Cooperative Agreement No. AID-OAAL-15-00001.Funding agency played vital role for designing of the study and writing of the manuscript.

\section{Availability of data and materials}

The datasets of this study will be available from corresponding authors on genuine request.

\section{Ethics approval and consent to participate}

Not applicable. We did research on crop plant and did not handle animals along protected areas. Thus no ethics protocol was required to be followed.

\section{Consent for publication}

Not applicable. No permission is required to collect species location points and freely available worldclim data was used for bioclimatic variables https:// www.worldclim.org.

\section{Competing interests}

The authors declare that they have no competing interests.

\section{Author details}

${ }^{1}$ Central Department of Botany, Tribhuvan University, Kirtipur, Kathmandu, Nepal. ${ }^{2}$ Department of Environment, Ministry of Forests and Environment, Kathmandu, Nepal. ${ }^{3}$ Department of Plant Resources, Ministry of Forests and Environment, Kathmandu, Nepal. ${ }^{4}$ IPM-IL, Virginia Tech, Blacksburg, USA.

Received: 4 September 2019 Accepted: 26 March 2020

Published online: 06 April 2020

\section{References}

1. Shrestha AB, Wake CP, Mayewski PA, Dibb JE. Maximum temperature trend in Himalaya and vicinity: an analysis based on temperature records from Nepal for the period 1971-1994. J Clim. 1999;12:2775-86.

2. MOAC, Statistical Information on Nepalese Agriculture (2073/74). Ministry of Agriculture, Land Management and Cooperatives. Kathmandu. 2017.

3. Ghimire KH. Kodo kheti ra Biu utpadan prabidhi Janakari Patra. No. 5. LIBIRD, National Seed Bank, Department of Agriculture and Biodiversity International Nepal 2015. (in Nepali language).

4. Luitel DR, Siwakoti M, Jha PK, Jha AK, Krakauer N. Climate, distribution and cropping pattern of finger millet in Nepal: a review. Int J Agri Environ Res. 2017;3:3854-68.

5. FAO. Sorghum and millets in human nutrition. Rome: FAO Food and Nutrition Series. No. 68. 2005, 277.

6. Wafula WN, Korir NK, Ojulong HF, Siambi M, Gweyi-Onyango JP. Protein, calcium, zinc, and iron contents of finger millet grain response to varietal differences and phosphorus application in Kenya. Agronomy. 2018;8:24. https://doi.org/10.3390/agronomy8020024.

7. Saleh ASM, Zhang Q, Chen J, Shen Q. Millet grains: nutritional quality, processing, and potential health benefits. Compr Rev Food Sci Food Saf. 2013;12:281-95. https://doi.org/10.1111/1541-4337.12012.

8. NCVST. Vulnerability through the eyes of vulnerable: climate change induced uncertainties and Nepal's development predicaments.
Institute for Social and Environmental Transition-Nepal (ISETN). Kathmandu: Nepal Climate Vulnerability Study Team (NCVST); 2009.

9. MoSTE. Nepal: second national communication, submitted to UNFCCC. Kathmandu: Ministry of Science, Technology and Environment; 2014.

10. Hijioka Y, Lin E, Pereira JJ, Corlett RT, Cui X, Insarov GE. Asia. In: Barros VR, Field CB, Dokken DJ, Mastrandrea MD, Mach KJ, Bilir TE, et al., editors. Climate change 2014: impacts, adaptation, and vulnerability Part B: regional aspects contribution of working group II to the fifth assessment report of the intergovernmental panel on climate change. Cambridge: Cambridge University Press; 2014. p. 1327-70.

11. Shrestha AB, Wake CP, Dibb JE, Mayewski PA. Precipitation fluctuations in the Nepal Himalaya and its vicinity and relationship with some large scale climatological parameters. Int J Climatol. 2000;20(3):317-27.

12. Manandhar M, Vog DS, Perret SR, Kazama F. Adapting cropping systems to climate change in Nepal: a cross-regional study of farmers' perception and practices Regional. Environ Change. 2011;11:335-48.

13. Sujakhu NM, Ranjitkar S, Niraula RR, Pokharel BK, Schmidt-Vogt D, Xu J. Farmers ' perceptions of and adaptations to changing climate in the Melamchi valley of Nepal. Mt Res Dev. 2016;36:15-30. https://doi. org/10.1659/MRD-JOURNAL-D-15-00032.1.

14. Guisan A, Thuiller W. Predicting species distribution: offering more than simple habitat models. Ecol Lett. 2005;8:993-1009.

15. Guisan A, Tingley R, Baumgartner JB, Naujokaitis-Lewis I, Sutcliffe PR, Tulloch AIT, Buckley YM. Predicting species distributions for conservation decisions. Ecol Lett. 2013;16(12):1424-35. https://doi.org/10.1111/ ele.12189.

16. Phillips SJ, Anderson RP, Schapire RE. Maximum entropy modeling of species geographic distributions. Ecol Model. 2006;190(3-4):231-59.

17. Paudel MN, Joshi BK, Ghimire KH. Management of status of agricultural plant genetic resources in Nepal. Agronomy J Nepal. 2016;4:75-91.

18. Boria RA, Olson LE, Goodman SM, Anderson RP. Spatial filtering to reduce sampling bias can improve the performance of ecological niche models. Ecol Model. 2014;275:73-7.

19. Hijmans RJ, Cameron SE, Parra JL, Jones PG, Jarvis A. Very high resolution interpolated climate surfaces for global land areas. Int J Climatol. 2005;25:1965-78.

20. Gent PR, Danabasoglu G, Donner LJ, Holland MM, Hunke EC, Jayne SR, Lawrence DM, Neale RB, Rasch PJ, Vertenstein M. The community climate system model version 4. J Clim. 2011;24:4973-91.

21. Clarke L, Edmonds J, Jacoby H, Pitcher H, Reilly J, Richels R. Scenarios of greenhouse gas emissions and atmospheric concentrations. Sub-report 2.1 A of synthesis and assessment product 2.1 by the U.S. Climate change science program and the subcommittee on global change research. Department of Energy, Office of Biological \& Environmental Research, Washington DC. 2007, 154.

22. Fujino J, Nair R, Kainuma M, Masui T, Matsuoka Y. Multi-gas mitigation analysis on stabilization scenarios using AIM global model. Energy J. 2006;3:343-54

23. R Core Team. R: A language and environment for statistical computing. R foundation for statistical computing. Vienna. 2018. https://www.Rproject.org/.

24. Rogerson PA. Statistical methods for geography. London: Sage; 2001.

25. Shrestha UB, Sharma KP, Devkota A, Siwakoti M, Shrestha BB. Potential impact of climate change on the distribution of six invasive alien plants in Nepal. Ecological Indic. 2018;95:99-100. https://doi. org/10.1016/j.ecolind.2018.07.009.

26. Allouche O, Tsoar A, Kadmon R. Assessing the accuracy of species distribution models: prevalence, kappa and the true skill statistic (TSS). J Appl Ecol. 2006;43(6):1223-32.

27. Death G, Fabricius KE. Classification and regression trees: a powerful yet simple technique for the analysis of complex ecological data. Ecology. 2000;81:3178-92.

28. Pearce J, Ferrier S. Evaluating the predictive performance of habitat models developed using logistic regression. Ecol Model. 2000; 133:225-45.

29. Thapa S, Chitale V, Rijal SJ, Bisht N, Shrestha BB. Understanding the dynamics in distribution of invasive alien plant species under predicted climate change in Western Himalayas. PloS one. 2018;13:1-16.

30. Saxena R, Vanga SK, Wang J, Orsat V, Raghavan V. Millet for food security in the context of climate change: a review. Sustainability(MDPI). 2018;10:2228. https://doi.org/10.3390/su10072228. 
31. Zomer RJ, Trabucco A, Metzger MJ, Wang M, Oli KP, Xu J. Projected climate change impacts on spatial distribution of bioclimatic zones and ecoregions within the Kailash Sacred Landscape of China, India. Nepal. Clim Change. 2014;125:445-60. https://doi.org/10.1007/s10584-014-1176-2.

32. IFAD. NEPAL: Environmental and climate change assessment, prepared for IFAD's country strategic opportunities program 2013-2018. 2013.

33. Ranjitkar S, Sujakhu NM, Merz J, Kindt R, Xu J, Matin MA, Ali M, Zomer RJ. Suitability analysis and projected climate change impact on banana and coffee production zones in Nepal. PLoS ONE. 2014. https://doi. org/10.1371/journal.pone.0163916.

34. Grigorieva EA, Matzarakis A, de Freitas CR. Analysis of growing degreedays as a climate impact indicator in a region with extreme annual air temperature amplitude. Clim Res. 2010;42:143-54. https://doi. org/10.3354/cr00888.

35. Førland EJ, Skaugen TE, Benestad RE, Hanssen-Bauer I, Tveito OE. Variations in thermal growing, heating, and freezing indices in the Nordic Arctic, 1900-2050. Arct Antarct Alp Res. 2004;36:347-56.
36. Opole RA, Prasad PVV, Djanaguiraman M, Vimala K, Kirkham MB, Upadhaya HD. Thresholds, sensitive stages and genetic variability of finger millet to high temperature stress. J Agron Crop Sci. 2018. https://doi. org/10.1111/jac.12279.

37. http://geoapps.icimod.org/agricultureatlas/atlas/index.html.

38. Amagain RB, Chhetri TB, Budhathoki MP, Khatiwada SP, Mudwari A. Variation on agro-morphological characteristics among Nepalese finger millet germplasm. Proceedings of the 27th National Summer crops workshop (vol. 2), Nepal Agriculture Research Council, Khumaltar Lalitpur. 2014.

\section{Publisher's Note}

Springer Nature remains neutral with regard to jurisdictional claims in published maps and institutional affiliations.
Ready to submit your research? Choose BMC and benefit from:

- fast, convenient online submission

- thorough peer review by experienced researchers in your field

- rapid publication on acceptance

- support for research data, including large and complex data types

- gold Open Access which fosters wider collaboration and increased citations

- maximum visibility for your research: over $100 \mathrm{M}$ website views per year

At BMC, research is always in progress.

Learn more biomedcentral.com/submissions 